\title{
Radiotracer Investigation of the Effect of Impeller Type on Mixing in Industrial Process Simulator
}

\author{
Simon Yao Adzaklo*, Christian Priesley Kofi Dagadu, Ishmael Iddisah Mumuni, \\ Patience Adwoa Serwah Adu, Hannah Asamoah Affum, Godfred Kofi Appiah, Alexander Coleman
}

National Nuclear Research Institute, Ghana Atomic Energy Commission, Legon-Accra, Ghana

Email: *s.yadzaklo@gaecgh.org

How to cite this paper: Adzaklo, S.Y., Dagadu, C.P.K., Mumuni, I.I., Adu, P.A.S., Affum, H.A., Appiah, G.K. and Coleman, A. (2018) Radiotracer Investigation of the Effect of Impeller Type on Mixing in Industrial Process Simulator. Journal of Applied Mathematics and Physics, 6, 468-474. https://doi.org/10.4236/jamp.2018.63043

Received: February 3, 2018

Accepted: March 11, 2018

Published: March 14, 2018

Copyright (c) 2018 by authors and Scientific Research Publishing Inc. This work is licensed under the Creative Commons Attribution International License (CC BY 4.0).

http://creativecommons.org/licenses/by/4.0/

\begin{abstract}
Radiotracer technology has been applied in industry for the investigation of process performance, online monitoring of conditions of process units, troubleshooting and diagnosing anomalies including mixing conditions in continuous stirred tank reactors. In this study, radiotracer methodology was used to carry out investigation on a laboratory water flow rig which serves as simulator of industrial processes. The aims of the investigation were to assess: i) the effect of impeller type on mixing and ii) the fluid dynamics of the water in the vessels since both the vessels and the impellers were redesigned and reconstructed. Four similar vessels in series circuit with different impeller configurations were investigated. Tank 1 has 1 axial impeller, Tank 2 has 2 axial impellers, Tank 3 has 2 radial impellers and Tank 4 has no impeller. The data were collected by introducing $8 \mathrm{mCi}$ liquid technetium- $99 \mathrm{~m}$ at the inlet stream of the vessels and the gamma signal was detected with thallium activated NaI detector placed at the outlet of the vessels. Residence Time Distribution (RTD) curves for the outlet tracer concentration were generated from which the Mean Residence Time (MRT) and the variance were calculated by the method of moments. The extent of material mixing in the vessels was inferred from the variances and the fluid dynamics was obtained by modeling. The extent of mixing was highest in Tank 2 followed by Tank 3, and Tank 4 gave the poorest mixing. The outlet response curves were fitted with mathematical models using DTS pro and "RTD Software". The best fit for Tanks 2, 3 and 4 was Perfect Mixers in Series with Exchange (PMSE) model while Perfect Mixers in Series with Recycle (PMSR) model best described the fluid dynamics of the material in Tank 1.
\end{abstract}

\section{Keywords}

Axial, Impellers, Mixing, Radial, Radiotracer 


\section{Introduction}

Mixing by agitation plays a very important role in industrial reactors including metallurgical reactors used for mineral processing. Industrial mixing is carried out for many reasons but the main aim is to provide mass transfer of material to promote better contact between reactor contents in order to obtain the required product quality in the shortest possible time [1]. However, many industrial mixing operations are either inefficient or more than enough, mainly due to improper reactor design. The primary cause is the lack of understanding of the mixing process which could be attributed to the complex nature of impeller-induced flows in stirred vessels [2]. This leads to poor product quality and overconsumption of energy that eventually results in high production costs [3] [4]. Therefore, there is the need for in-depth studies of mixing operations to determine the performance of mixing vessels. A good understanding of mixing operations in stirred vessels will enhance optimal design and help modify existing processes in order to minimize capital and running costs [5].

The need to understand and improve on mixing in industrial processes is on the increase in recent times. This is mainly to enable the improvement on the design and operation of mixing systems, which will in turn enhance safety and economic issues. However, industrial experimentation is costly due to a number of reasons including large volume of materials to handle, complex machinery and logistical issues [6]. Hence most researchers including [5] [7] [8] [9] resort to the use of laboratory experimental facilities for simulation and modeling of flow systems applicable to industrial processes.

Many concepts have been used to describe the mixing characteristics of non-ideal reactors but the most commonly used ones are the residence time distribution (RTD), the quality of mixing and the mathematical model that describes the system. Any or a combination of these concepts are considered when describing deviations from the mixing patterns assumed in ideal reactors [10] [11]. In this study, radiotracer methodology was used to carry out investigation on a laboratory water flow rig which serves as simulator of industrial processes. The aims of the investigation were to assess the effect of impeller type on mixing and also determine the fluid dynamics of the material in the vessels.

\section{Methodology}

Radiotracer application technique was used in this investigation with the help of laboratory experimental flow rig which serves as industrial process simulator

\subsection{Experimental System}

The flow rig was originally installed by the IAEA in 2008 through the IAEA/ AFRA project, RAF/8/040 [12]. The original flow rig has limitations which could not make it adaptive for research on real flow conditions applicable to industrial processes. The rig therefore went through various phases of modifications over the years. The current modification on the rig include redesigning and recon- 
struction of the impellers, upgrading the power of each stirrer motor to $0.5 \mathrm{hp}$, and also restructuring for open circuit operations which is mostly the case in industrial process plants. The experimental unit consists of four similar tanks in series on open circuit. The tank configurations are shown in Figures 1(a)-(d).

Tank 1 is fitted with a single axial impeller, Tank 2 with twin axial impellers mounted on the same shaft and Tank 3 by twin radial impellers also mounted on the same shaft. Tank 4 has no impellers. The main aim is to study the effect of impeller configuration on the extent of mixing and the fluid dynamics of materials in the tanks.

\subsection{Experimental Procedure}

The data was collected by introducing $8 \mathrm{mCi}$ liquid technetium- $99 \mathrm{~m}$ at the inlet stream of Tank 1 and the gamma signals were collected with thallium activated $\mathrm{NaI}$ detector placed at the outlet of each tank. The detectors were connected to Altaix data acquisition system which consists of Caesar 12 USB CTR-15 counter and a laptop for visual display of the signals [13]. Figure 2 and Figure 3 show the data acquisition system and visual display of online experimental tracer concentration curves respectively.
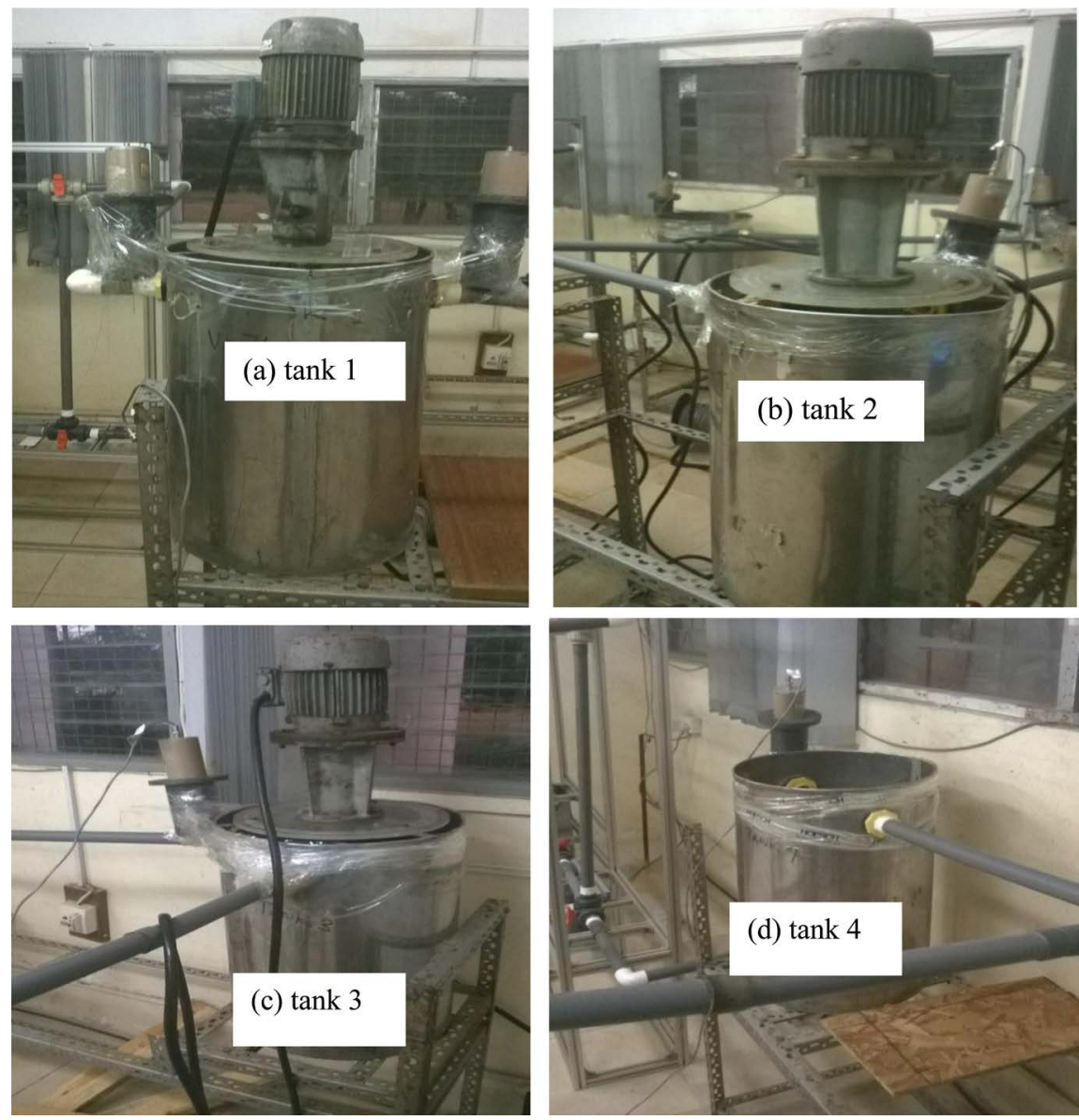

Figure 1. Tanks with different impeller configurations. (a) 1 axial impeller; (b) 2 axial impellers; (c) 2 radial impellers; (d) no impeller no baffle. 


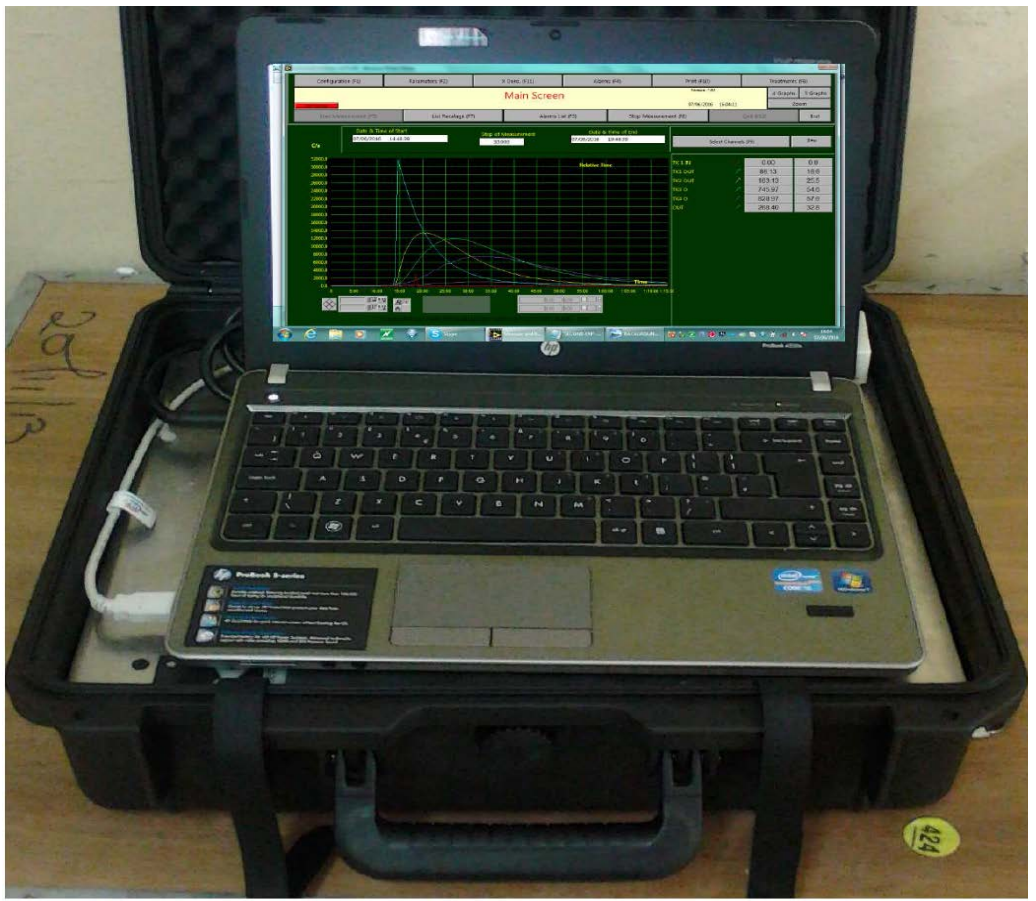

Figure 2. Altaix data acquisition system.

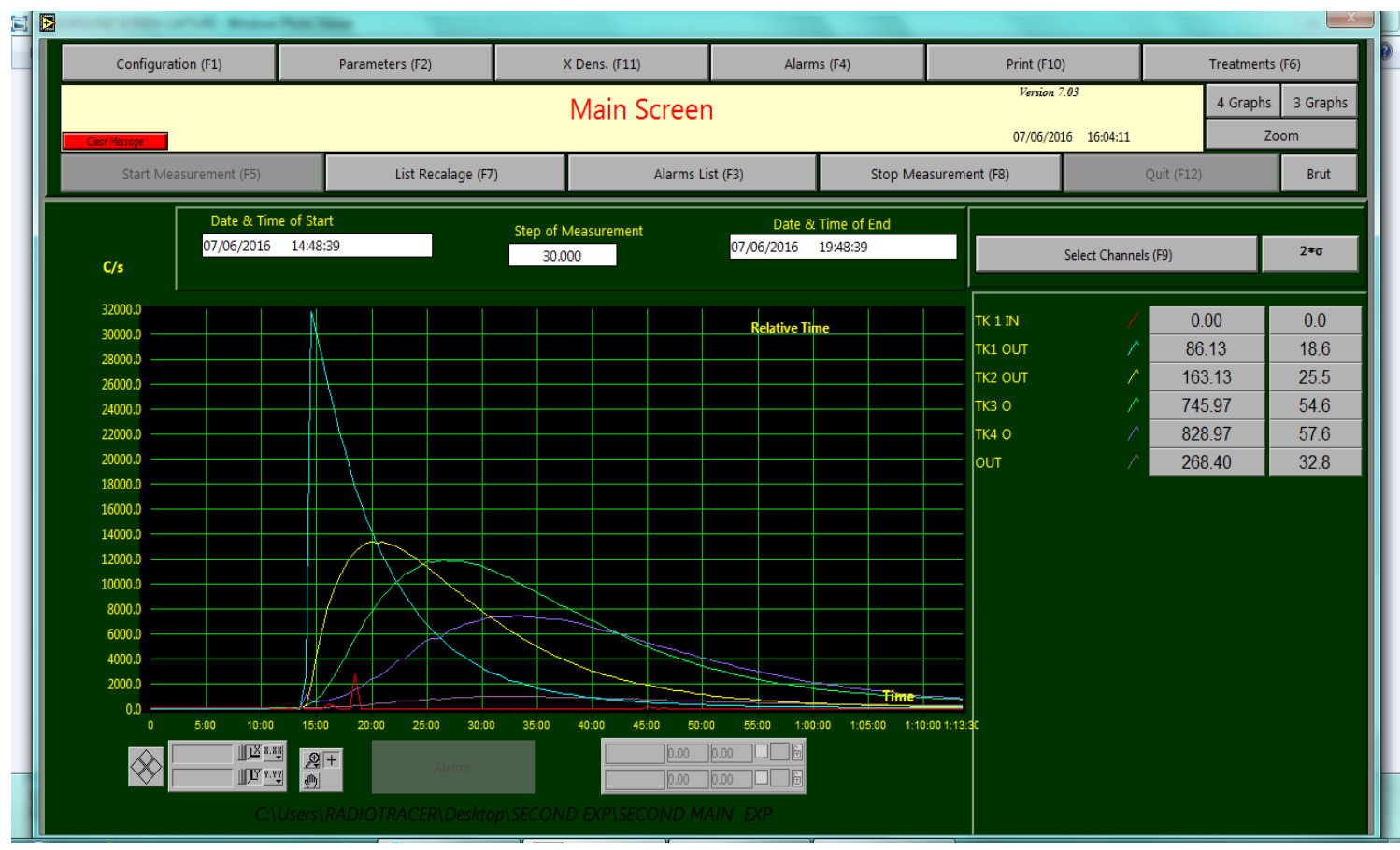

Figure 3. Visual display of online experimental tracer concentration curves.

\section{Results and Discussions}

Residence Time Distribution (RTD) curves for the outlet tracer concentration were generated from which the Mean Residence Time (MRT) and the variance were calculated by the method of moments. The experimental parameters and the model parameters are presented in Table 1 and Table 2 respectively. 
Table 1. Experimental parameters.

\begin{tabular}{ccccc}
\hline $\begin{array}{c}\text { Experimental } \\
\text { Parameters }\end{array}$ & $\begin{array}{c}\text { Tank 1 } \\
\text { (1 axial impeller) }\end{array}$ & $\begin{array}{c}\text { Tank 2 } \\
(2 \text { axial impeller) }\end{array}$ & $\begin{array}{c}\text { Tank 3 } \\
\text { 2 radial impeller) }\end{array}$ & $\begin{array}{c}\text { Tank 4 } \\
\text { (no impeller) }\end{array}$ \\
\hline Tank height $(\mathrm{cm})$ & 61.0 & 61.0 & 61.0 & 61.0 \\
Free board height $(\mathrm{cm})$ & 10.0 & 10.0 & 10.0 & 10.0 \\
Tank diameter (cm) & 38.2 & 38.2 & 38.2 & 38.2 \\
Material volume (lit) & 58.4 & 58.4 & 58.4 & 58.4 \\
Flow rate (lit/min) & 10 & 10 & 10 & 10 \\
Theoretical MRT (min) & 5.8 & 5.8 & 5.8 & 5.8 \\
Exp. MRT per tank (min) & 5.3 & 7.5 & 7.1 & 5.1 \\
Exp. Variance per tank, & 42.4 & 86.3 & 57.7 & 26.6 \\
$\sigma^{2}$ (min $\left.{ }^{2}\right)$ & & & & \\
\hline
\end{tabular}

Table 2. Model parameters.

\begin{tabular}{|c|c|c|c|c|}
\hline Model parameters & $\begin{array}{c}\text { Tank } 1 \\
\text { (1 Axial impeller) } \\
\text { (PMSR model) }\end{array}$ & $\begin{array}{c}\text { Tank } 2 \\
\text { (2 axial impellers) } \\
\text { (PMSE model) }\end{array}$ & $\begin{array}{c}\text { Tank } 3 \\
\text { (2 radial impellers) } \\
\text { (P MSE model) }\end{array}$ & $\begin{array}{c}\text { Tank } 4 \\
\text { (no impeller) } \\
\text { (PMSE model) }\end{array}$ \\
\hline Taul (min) & 5.0 & -- & -- & -- \\
\hline Tau2 (min) & 1 & -- & -- & -- \\
\hline J1 (-) & 2.1 & -- & -- & -- \\
\hline $\mathrm{J} 2(-)$ & 1 & -- & -- & -- \\
\hline$\alpha(-)$ & 0.13 & -- & -- & -- \\
\hline Cum. $t_{a c t}(\min )$ & -- & 9.5 & 17.2 & 22.8 \\
\hline $\mathrm{t}_{\mathrm{m}}(\mathrm{min})$ & -- & 3.8 & 11.4 & 1 \\
\hline$J(-)$ & -- & 2.8 & 3.2 & 3.7 \\
\hline $\mathrm{k}(-)$ & -- & 0.36 & 0.15 & 0.1 \\
\hline $\begin{array}{c}\text { Per tank } \mathrm{MRT}_{\text {total }} \text {, } \\
\bar{t}(\min )\end{array}$ & 5.7 & 7.3 & 6.9 & 5.3 \\
\hline $\begin{array}{c}\text { Per tank variance, } \\
\sigma^{2}\left(\min ^{2}\right)\end{array}$ & 40.4 & 80.7 & 66.3 & 27.6 \\
\hline
\end{tabular}

The extent of mixing was inferred from RTD analysis. The parameters in Table 1 and Table 2 indicate that the extent of mixing in Tank 2 is highest followed by Tank 3 and Tank 4 shows the poorest mixing [10]. Thus for this investigation, axial impellers show a better mixing than radial ones. Agitators and baffles aid in mixing [14] and since Tank 4 has none of these mixing aids, it is not surprising that the mixing was poorest in this tank. Figures 4(a)-(d) show the experimental and model outlet tracer concentration curves. The tracer outlet response curves were also fitted with mathematical models using DTSPRO and "RTD Software" in order to determine the fluid dynamics of materials in each tank [15]. The flow dynamics in Tanks 2, 3 and 4 are best described by PMSE model but that of Tank 1 is best described by PMSR model. The two softwares 

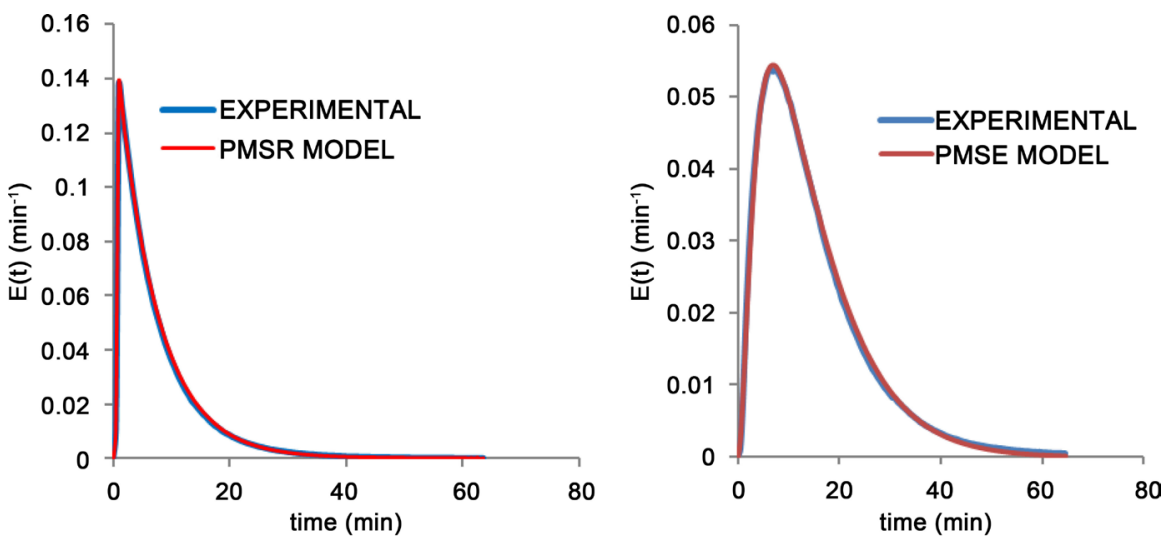

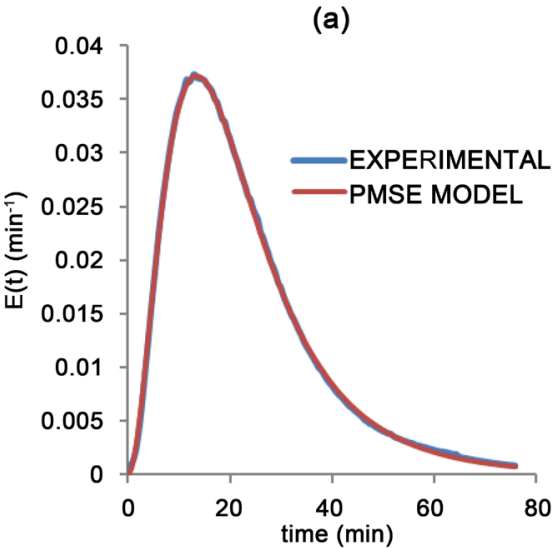

(c)

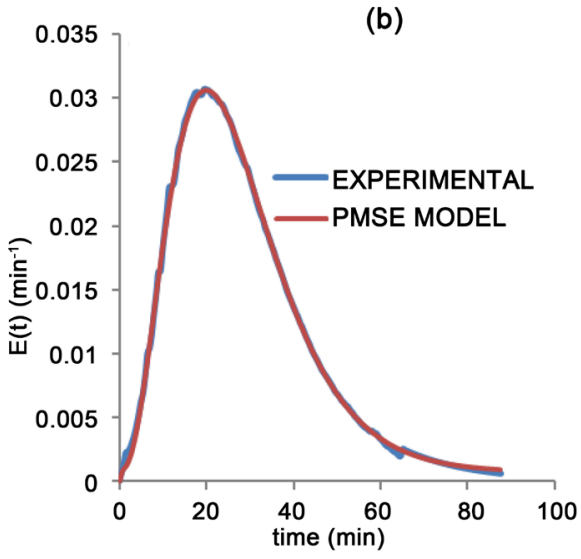

(d)

Figure 4. Experimental and model outlet tracer concentration curves. (a) Tank 1: 1 axial impeller; (b) (a) Tank 2: 2 axial impellers; (c) Tank 3: 2 radial impellers; (d) Tank 4: No impeller, no baffle.

were used in the modeling because DTSPRO did not have PMSR model which best fit Tank 1 data. Hence the "RTD software" was used in modeling the flow of materials in Tank 1.

\section{Conclusions}

Radiotracer methodology was used to carry out investigation on a laboratory water flow rig which serves as simulator of industrial processes. The conclusions from the simulator are that:

- The extent of mixing for axial flow impellers for the simulator was better than that of radial flow impellers for this investigation.

- The fluid dynamics of materials in the tanks were best described by PMSE and PMSR models.

Optimum mixing time of the materials in the vessel could be investigated in future for the various impeller configurations.

\section{Acknowledgements}

The authors are very grateful to the IAEA for the technical support and the Radiotherapy Unit of the Korle-Bu Teaching Hospital, Accra, Ghana for the supply 
of radiotracer for this investigation.

\section{References}

[1] Kuncewicz, C., Szulc, K. and Kurasinski, T. (2005) Hydrodynamics of the Tank with a Screw Impeller. Chemical Engineering and Processing, 44, 766-774. https://doi.org/10.1016/j.cep.2004.08.006

[2] Delvigne, F., Destain, J. and Thonart, P. (2005) Structured Mixing Model for Stirred Bioreactors: An Extension to the Stochastic Approach. Chemical Engineering Journal, 113, 1-12. https://doi.org/10.1016/j.cej.2005.06.007

[3] Distelho, M.F.W. and Marquis, A.J. (2000) Scalar Mixing in the Vicinity of Two Disk Turbines and Two Pitched Blade Impellers. Chemical Engineering Science, 55, 1905-1920. https://doi.org/10.1016/S0009-2509(99)00464-9

[4] Jayanti, S. (2001) Hydrodynamics of Jet Mixing in Vessels. Chemical Engineering Science, 56, 193-210. https://doi.org/10.1016/S0009-2509(99)00588-6

[5] Dagadu, C.P.K., Stegowski, Z., Sogbey, B.J.A.Y. and Adzaklo, S.Y. (2015) Mixing Analysis in a Stirred Tank Using Computational Fluid Dynamics. Journal of Applied Mathematics and Physics, 3, 637-642. https://doi.org/10.4236/jamp.2015.36076

[6] Lundkvist, P. (2012) Experiments and Capability Analysis in Process Industry. Licentiate Dissertation, Lulea University of Technology, Lulea. https://www.diva-portal.org/smash/get/diva2:990278/FULLTEXT01.pdf

[7] Adzaklo, S.Y., Dagadu, C.P.K., Adu, P.S., Affum, H.A. and Sogbey, B.J.A.Y. (2016) Investigation of Feed Dynamics in Clinker Grinding Mill by Residence Time Distribution Method. E-Journal of Science \& Technology, 11, 39-46.

[8] Kasban, H., Zahran, O., Arafa, H., El-Kordy, M., Elaraby, S.M.S. and Abdel-Samie, F.E. (2010) Laboratory Experiments and Modeling for Industrial Radiotracer Applications. Applied Radiation and Isotopes, 68, 1049-1056.

https://doi.org/10.1016/j.apradiso.2010.01.044

[9] Yeoh, S.L., Papadakis, G. and Yianneskis, M. (2004) Numerical Simulation of Turbulent Flow Characteristics in a Stirred Vessel using the LES and RANS Approaches with the Sliding/Deforming Mesh Methodology. Chemical Engineering Research and Design, 82, 834-848. https://doi.org/10.1205/0263876041596751

[10] IAEA (2008) Radiotracer Residence Time Distribution Method for Industrial and Environmental Applications. Training Course Report Series 31, Vienna.

[11] Fogler H.S. (2006) Elements of Chemical Reaction Engineering. 4th Edition, Pearson Education, Inc., Upper Saddle River.

[12] Dagadu, C.P.K. (2012) Investigation into the Use of Radionuclide Generators for Radiotracer Applications in Ghanaian Industries. Country Report, IAEA Research Contract No. 14367.

[13] Altaix Systems (2012) Caesar 12 Software User Manual. Villebon-sur-Yvette.

[14] Dagadu, C.P.K., Akaho, E.H.K., Danso, K.A., Stegowsk, Z. and Furman, L. (2012) Radiotracer Investigation in Gold Leaching Tanks. Applied Radiation and Isotopes, 70, 156-161. https://doi.org/10.1016/j.apradiso.2011.09.003

[15] PROGEPI (2000) DTSPRO V 4.2 Software Instruction Manual. Nancy. 